\title{
Toward converting some individual parks into smart parks in Kerbela city
}

\author{
Hamid Athab Al-Jameel ${ }^{1, *}$ \\ ${ }^{1}$ University of Kufa, Najaf, Iraq
}

\begin{abstract}
The city of Kerbela is from the famous holy cities in Iraq and in the world where the holy shrine of Imam Hussein there. This city suffers from lack of suitable parking area for the vehicles coming to this city. This study selects a surrounding section which is approximately the same as other sections surrounding the city center. Knowing the problems in this section give a comprehensive picture for parking problems in the whole city. The study area has serious parking problems; therefore five off-street parks have been surveyed for two days during ordinary day and the other one in religious day (Thursday at day and night). Other types of data have been collected such as vehicular flow and pedestrian flow in order to select the best management for this area. The location of these five parks is on the north side of the city facing the main arterial street surrounding the holy city and in the opposing direction to the main garage called Al-Garage Al-Muhad from which different trips end and start. The analysis results of field data show that parking behavior differs in the ordinary day from the day of religious issues. It is a specific location has been assigned for one park with multi-stories in the same area as alternative of these separated parks. In addition, it was found that there is a need for managing pedestrian movement related to the parking vehicles in this area. This study also suggests using smart parking system as first step towards building intelligent transportation system to manage the parking facilities.
\end{abstract}

\section{Introduction}

The holy city of Kerbela is one of the famous holy cities (Al-Najaf, Baghdad and Samara) in Iraq in terms of number of attracting tourists from Iraq and other parts in the world. The number of visitors mainly exceeds 10 million persons for more than three times in year [1]. Therefore, a lot of vehicles used to transfer those visitors. Consequently, there is an urgent need for parking area for those vehicles.

Parking facilities are a necessary component of any transportation system to store vehicles when they are not in use. However, as parking facilities grow large, advanced methods of parking management are needed to reduce inefficiencies in finding available parking spaces [2].

Parking lots usually accompany buildings that house members of institutions (e.g. schools, churches) or organizations (e.g. business establishments) that operate motor vehicles. These plots of land can have capacities ranging from a few vehicles to hundreds of vehicles. Lots are normally paved and have paint marks that outline the space designated for each vehicle. Parking spots are normally arranged in rows, and aisles provide access to the spaces in each row [2]. Smart parking systems (SPS) have arisen in high density population areas to help patrons easily find parking in a crowded facility [2].
As mentioned above, there is a need to manage parking area. SPS is one of these methods as indicated in the next section.

The aim of this study is to evaluate some specific isolated parks distributed arbitrary along section of road up to $500 \mathrm{~m}$ in length. Then, study the characteristics of these parks, pedestrians' movements and flow rate for the arterial road in the area under study.

\section{Smart parking system (SPS)}

As parking facilities grow larger and demand increases for parking, systems to help drivers find available parking become necessary to better manage the time and resource costs associated with the process of parking. These SPSs are able to monitor parking space usage and direct drivers to available spaces. The primary method of collecting usage information has come in the form of sensors at entrances and exits or sensors at individual parking spaces. Several methods of spreading availability information have been developed such as variable message signs and mobile/internet interfaces $[3,4]$.

Chinrungrueng and Sunantachaikul [5] described a proposed SPS that utilizes optical wireless sensors as its base technology for detecting the movement of vehicles and space occupancy. The authors solved the problem of false positives caused by pedestrians and other non-

* Corresponding author: hamid.aljameel@uokufa.edu.iq 
vehicular bodies by installing two optical heads, spaced apart, connected to one sensor. In this manner, the optical heads work together to judge the size of the passing object. Only those disturbances fitting the size of a motor vehicle trigger the sensor to register the presence of the vehicle.

Yan-Zhong et al. [6] developed an SPS that utilizes individual sensors for every parking space. These sensors are connected to a wireless network to inform drivers of a lot's real-time capacity and the location of empty spots. Sensors are deployed at every parking space and monitor the space's occupancy. This information is dispersed to the sink node that collects the information and relays it to a management station as indicated in Figure 1. The management system sends out the information to a sign at the entrance informing drivers of the parking utilization. It also updates the appropriate guiding nodes located at every major intersection. These guide nodes direct drivers toward available parking.
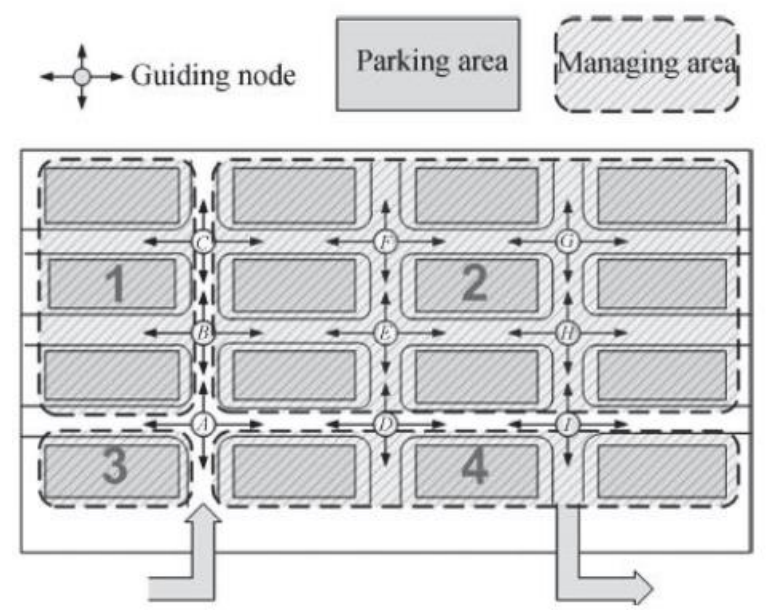

Fig. 1. Parking management system using guiding nodes and grouped parking spaces [6].

The guiding nodes do not direct drivers to individual spots, but rather, they guide drivers to parking areas with unused capacity. This is an efficient scheme and is depicted in Figure 1. However, the technology (e.g. sensors, routing protocol) is not perfect based on preliminary experiments conducted by Yan-Zhong et al. [6]. Improved methods for improving data transfer reliability, among other issues, are recommended bythe authors for further testing. Lu et al. [4] published a paper on a smart parking scheme for large parking lots called SPARK (i.e. Smart Parking).

A new type of SPS has been proposed by Geng and Cassandras [7]. This system exploits technologies for parking space availability detection and for driver localization and which assigns optimal parking spots to drivers instead of only supplying guidance to them as in Figure 2. They also described the system infrastructure and basic "smart parking" procedure.

Adhatarao, et al. [8] conducted their study to test the application of SPS using wireless sensor networks (WSNs). They successfully built and test SPS using light sensors to automatically determine the use of parking spaces in a parking area and providing occupied and free parking spaces to drivers. This will help drivers in finding suitable parks with low cost and time.

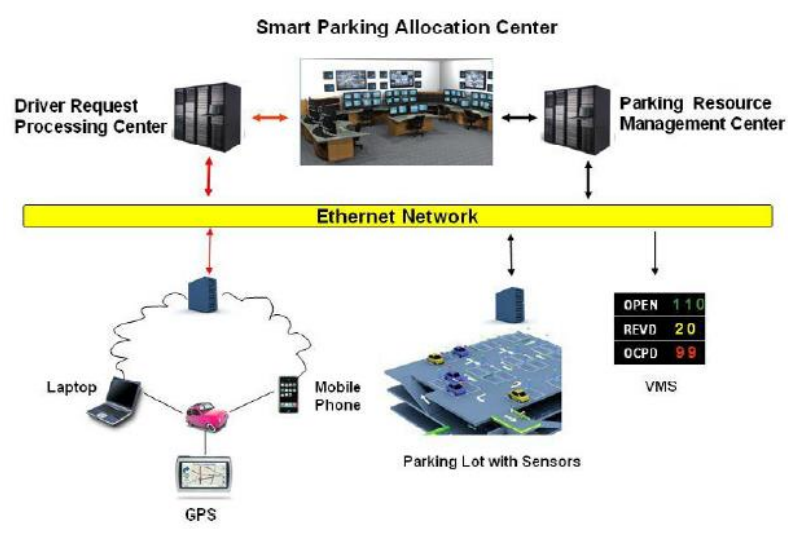

Fig. 2. "Smart Parking" Infrastructure (Geng and Cassandras , 2012).

Srotyr, et al. [9] proposed telematics system to provide information for truck drivers about the predicted occupancy for the nearest parking lot. They tested their model and there was encouraging results.

Majidi et al. [10] propose an exponential smoothing and multi-objective decision-making by using cloudbased methods to find the best parking place, taking into consideration of the park-cost for the driver as shown in Figure 3.

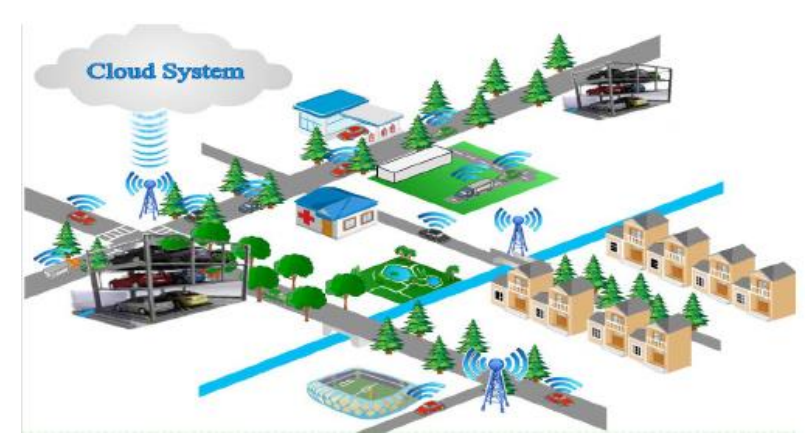

Fig. 3. An example of inter-vehicle communication [10].

The proposed system is capable of calculating i) a parking place for a specific location (the popularity of a parking place), ii) the possibility of vacancy of a parking place at the time, iii) anticipating the situation of a parking at a particular time, and iv) performing the multi-criteria decision-making among the criteria that the driver or the system supplies. With the assistance of the objective function according to the chosen criteria and the current parking situation, the system points the best places in order of priorities of the driver.

\section{The parks understudy}

Generally, in Kerbela city one could notice two demands for parking: one in ordinary day and the other in day 
which there is a religious activity (every Thursday and Friday in each week during a year). Figure 4 shows the location of area understudy and Layout A (see Appendix A) indicates the land use for area understudy.

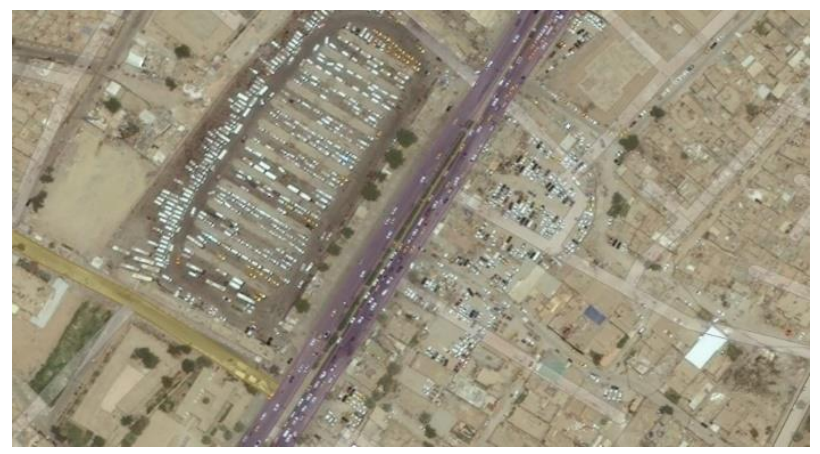

Fig. 4. Study area with five parking lots.

Moreover, Figure 5 demonstrates the location of proposed muti-story park in the study area as suggested by the authorities in the city. The importance of study area currently is due to two reasons: firstly, it is the closest to city center where holy shrines are located which are the major trip generators and distributors. Secondly, it is similar to other surrounding parts of city center.

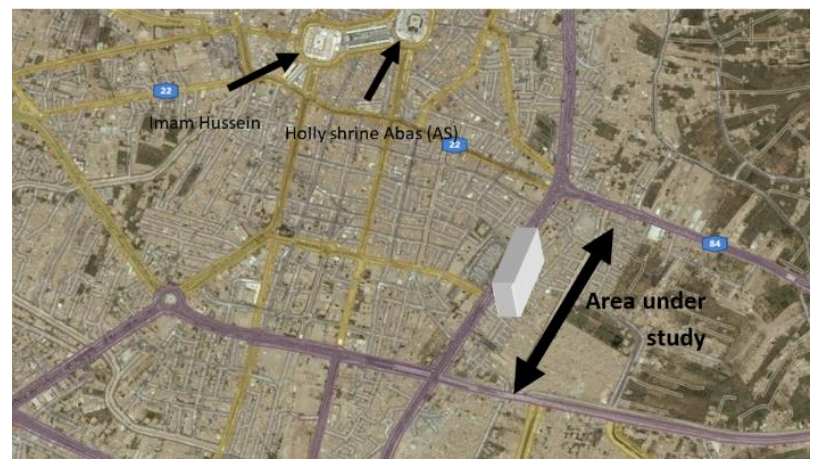

Fig. 5. Location of proposed Multi-story Park.

\section{Data collioection}

To understand the whole vision in the study area and know more about the parking behaviour, five parks have been selected in addition to determine the pedestrian and vehicle flow for two days (Wednesday and Thursday).

Three types of parking surveys have been adopted: the number of vehicles entering and leaving, the origin and destination survey (interviews) and turnover calculations. These surveys have been conducted by a group of engineers. They have been distributed to cover different activities such as parking survey, counting vehicles using the main road in the study area, and pedestrian crossing the main road within parking area only.

\section{Data analysis}

As mentioned above, several surveys have been conducted in this study such as flow rate, pedestrian flow and parking surveys.

\subsection{Flow rate}

Flow data have been collected every $15 \mathrm{~min}$ by the observers. Enumerators have been distributed at the entrance of the main road with the boundary of study area as indicated in Figure 6. According to flow data, it was observed that the peak hour $(3700 \mathrm{veh} / \mathrm{hr})$ was from 8:30 to $9: 30$ as indicating in Figure 7 on Wednesday. Whereas, Figure 8 shows flow on Thursday. This period represents the time from 2:30 P.M until 10:00 P.M. It was observed that the peak hour $(3500 \mathrm{veh} / \mathrm{hr})$ for this period from 5:30-6:30 P.M. The flow has been determined just for the direction coming to the city (entering the city) and is in the side of parking area. Then, the maximum value of the peak flow is on Wednesday.

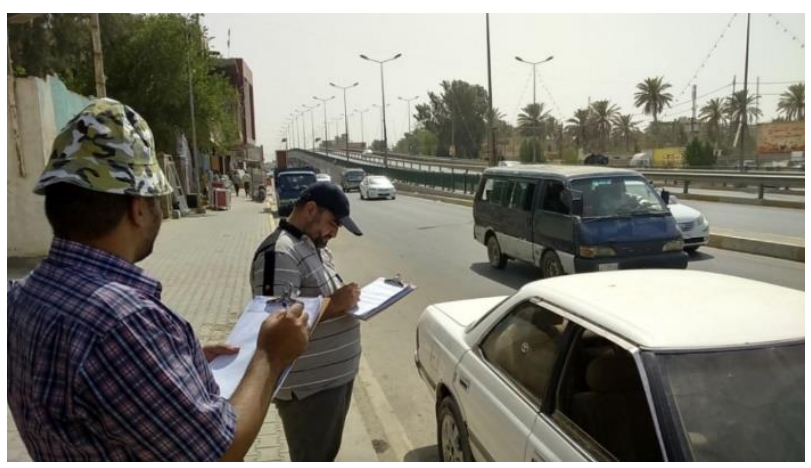

Fig. 6. Enumerators collecting field data.

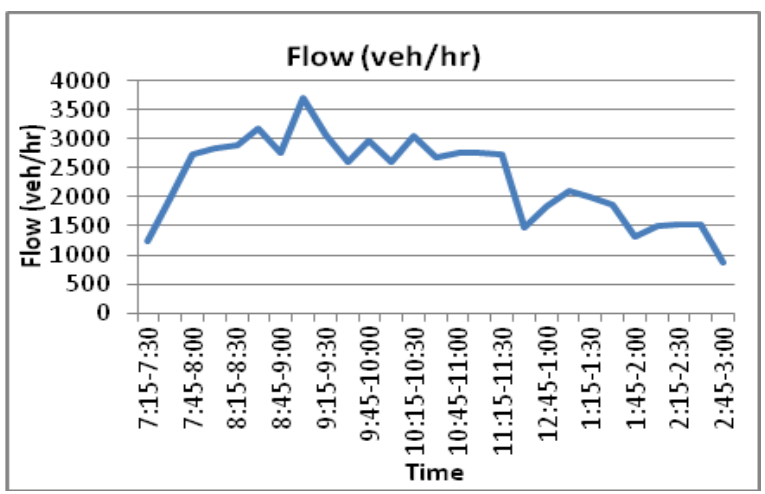

Fig. 7. Peak hour volume for the main road/ Wednesday. 


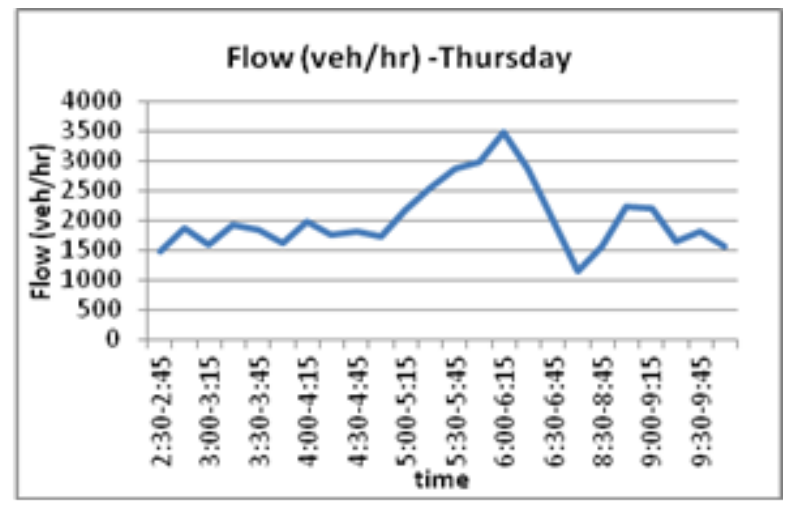

Fig. 8. Peak hour volume for the main road-Thursday.

\subsection{Pedestrian flow}

According to the survey for two days, it was noticed that the highest flow for pedestrian crossing the main road along the study area was on Thursday. Figure 9 demonstrates the number of pedestrian crossing in both directions. Thereupon, this high flow rate of pedestrians could be attributed to the high number of visitors crossing the street either coming from taxi/public transportation or parking vehicles in the isolated parks (parks under study). This leads to high interference with the vehicular flow.

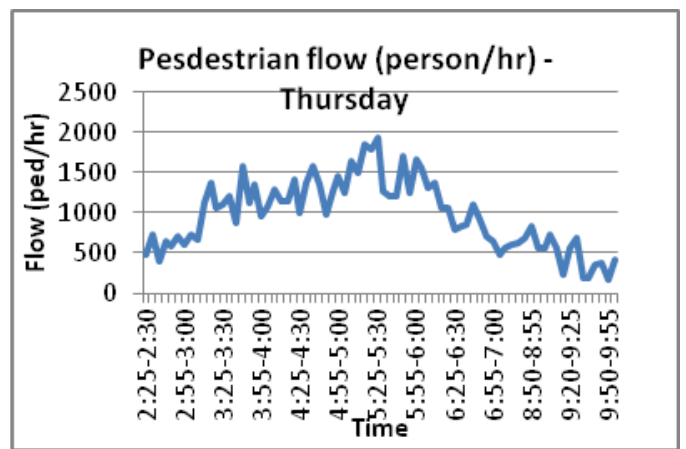

Fig. 9. Pedestrian flow crossing the main road.

It has been found that the number of pedestrian crossing the main road at the peak hour is 1900 ped per hour. This leads to high interaction between pedestrian and traffic stream because there is no specific area for pedestrian to cross. This results in high congestion and creates a lot of bottlenecks along this section as indicated in Figure 10.

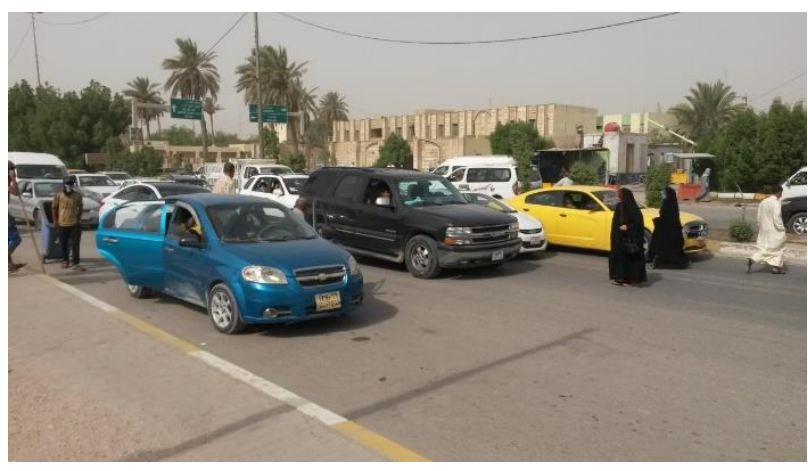

Fig. 10. Pedestrian interactions with traffic stream.

\subsection{Parking survey}

Parking surveys have been conducted for entering and exiting vehicles to obtain accumulated vehicles. Figures 11 and 12 state the accumulative curve for Imam Ridah Park. The number of spaces in Imam Ridah Park is 90. Table 1 shows that the number of vehicles in and out the park. The survey started at 7:30 A.M and the number of parked vehicles was 30 . Then, the occupancy for each park has been determined according to in-out accumulated vehicles.

Moreover, the average turnover has been evaluated by determining the number of spaces and the number of vehicles using these spaces. This has been conducted by checking the plate number of each vehicle for each park every 15 minutes by the observers. If the average turnover is 1 this means that the spaces has only occupied by one vehicle and if it 2 means 2 vehicles have used it. The calculated turnover for this park is 1.25 for Wednesday.

Figure 11 shows that the percentage of occupancy for Wednesday which reaches up to $65 \%$ from the capacity of park. This value has been found that the same results for the several days (except Thursday and Friday) in previous weeks according to data recording for these parks for each individual park form security purposes. These trips were found as a result of coming to governmental offices there. Whereas, on Thursday, the purpose of these trips was to visit the holy shrines in the city that means they were for religious issues. Figures from 13 to Figure 16 demonstrate the percentage of accumulated parking vehicles for Al-Gadeer, Al-Anwar, and Bab Tureag.

In fact, all other types of parks behave the same during the Thursday night (i.e. at 6:00 P.M reach their capacity). However, Al-Gadeer Park is closed during Friday and Saturday. Moreover, this park is closed up to 2:00 P.M. the number of spaces is 41. The turnover is 1. 


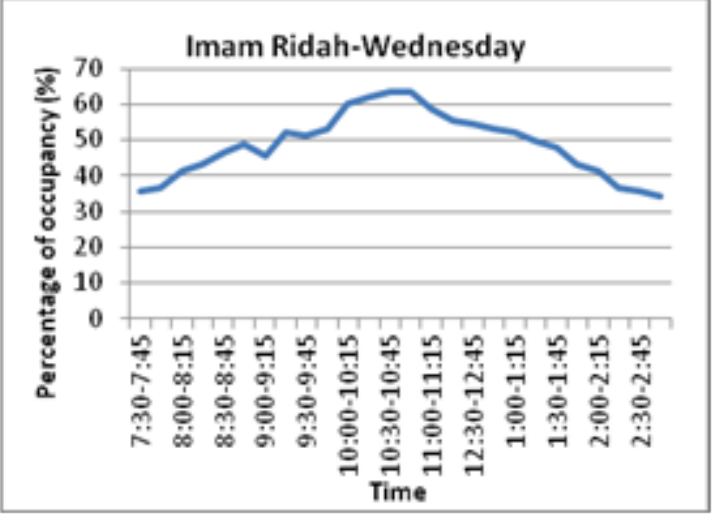

Fig. 11. Accumulated parking vehicles for Imam RidahWednesday.

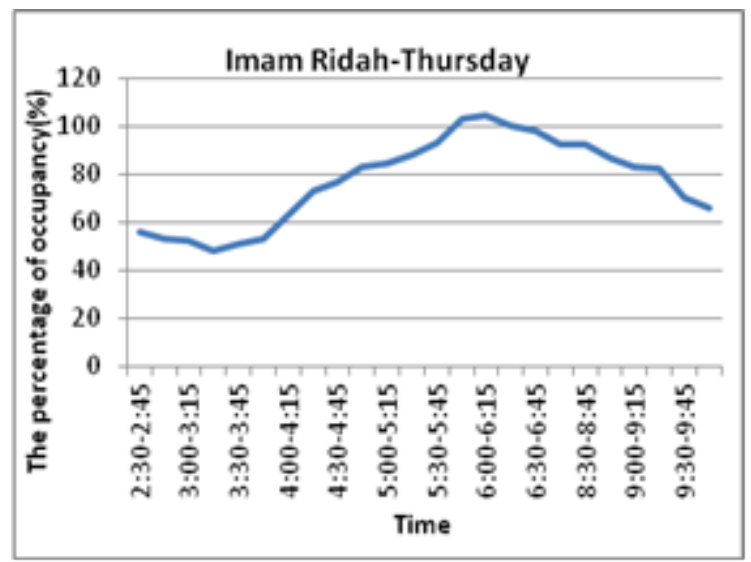

Fig. 12. Accumulated parking vehicles for Imam RidahThursday.

Al-Anwar and Baghdad parks were considered as one park because they share in one entrance. The total number of spaces is 85 . It was noticed that the accumulated flow during Wednesday operated under capacity by $40 \%$. Whereas on Thursday, the capacity was reached after 6:30 P.M. Then, parking volume starts decreasing due to returning of the visitors back to their origin. The average turnover is 1.35 and 1.4 for AlAnwar and Baghdad parks, respectively.

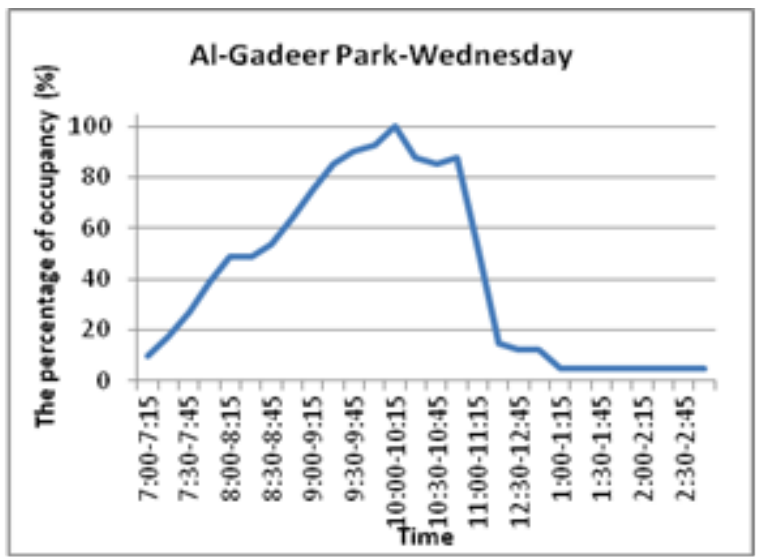

Fig. 13. Accumulated parking vehicles for Al-Gadeer Park-Wednesday.

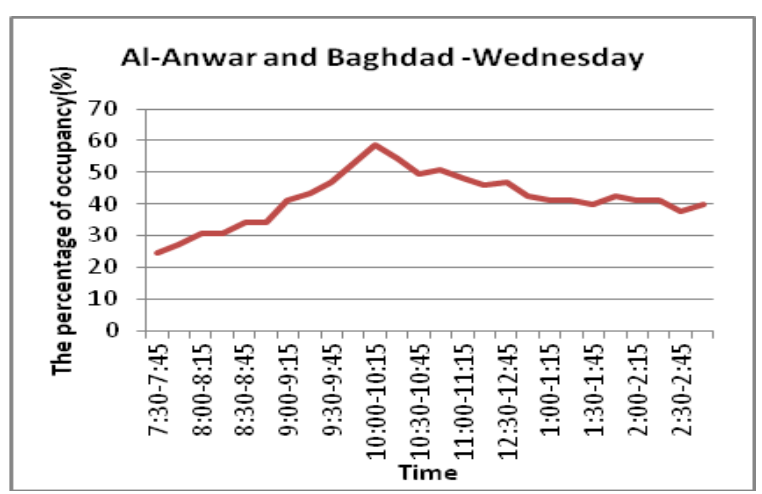

Fig. 14. Accumulated parking vehicles for Al-Anwar and Baghdad Parks-Wednesday.

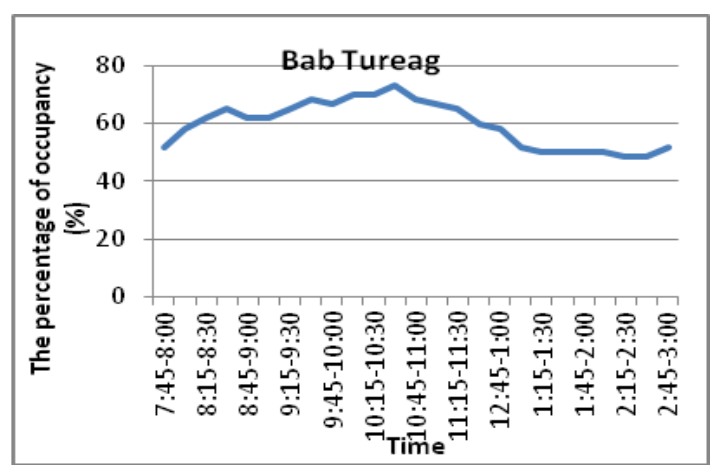

Fig. 15. Accumulated parking vehicles for Bab Tureag Parks-Wednesday. 
Table 1. Accumulated parked vehicles in Imam Ridah Park.

\begin{tabular}{||c|c|c|c|c|c|c|c||}
\hline \hline TIME & IN & OUT & $\begin{array}{c}\text { ACCUMULATED } \\
\text { VEHICLES }\end{array}$ & TIME & IN & OUT & $\begin{array}{c}\text { ACCUMULATED } \\
\text { VEHICLES }\end{array}$ \\
\hline $7: 30-7: 45$ & 3 & 1 & 32 & $11: 15-11: 30$ & 1 & 1 & 53 \\
\hline $7: 45-8: 00$ & 4 & 3 & 33 & $11: 30-11: 45$ & 2 & 2 & 53 \\
\hline $8: 00-8: 15$ & 5 & 1 & 37 & $11: 45-12: 00$ & 0 & 0 & 53 \\
\hline $8: 15-8: 30$ & 3 & 1 & 39 & $12: 00-12: 15$ & 0 & 0 & 53 \\
\hline $8: 30-8: 45$ & 4 & 1 & 42 & $12: 15-12: 30$ & 1 & 1 & 53 \\
\hline $8: 45-9: 00$ & 5 & 3 & 44 & $12: 30-12: 45$ & 2 & 3 & 52 \\
\hline $9: 00-9: 15$ & 3 & 6 & 41 & $12: 45-1: 00$ & 1 & 3 & 50 \\
\hline $9: 15-9: 30$ & 8 & 2 & 47 & $1: 00-1: 15$ & 1 & 2 & 49 \\
\hline $9: 30-9: 45$ & 3 & 4 & 46 & $1: 15-1: 30$ & 0 & 2 & 47 \\
\hline $9: 45-10: 00$ & 4 & 2 & 48 & $1: 30-1: 45$ & 0 & 2 & 45 \\
\hline $10: 00-10: 15$ & 8 & 2 & 54 & $1: 45-2: 00$ & 0 & 4 & 41 \\
\hline $10: 15-10: 30$ & 6 & 4 & 56 & $2: 00-2: 15$ & 2 & 4 & 39 \\
\hline $10: 30-10: 45$ & 3 & 2 & 57 & $2: 15-2: 30$ & 2 & 6 & 35 \\
\hline $10: 45-11: 00$ & 3 & 3 & 57 & $2: 30-2: 45$ & 2 & 3 & 34 \\
\hline $11: 00-11: 15$ & 2 & 6 & 53 & $2: 45-3: 00$ & 0 & 1 & 33 \\
\hline & & & & & & & \\
\hline
\end{tabular}

\subsection{Origin and destination survey}

Origin and destination study has been conducted by distributing the engineers at the entrance of each park. They ask the person involved in the trip about their origin, destination and the purpose of their trips. One of important thing has been noticed during the survey that all drivers used the parks were forced to answer these questions by the park office due to instructions from the authorities in the city for security issues.

Figure 17 indicates the percentages trips coming from different origins. Most of trips were interviewed from these isolated parks for the area under study demonstrates that Al-Najaf city at the first of other cities in terms of generating trips then Al-Basrah and Baghdad. These trips were classified as trips assigning for just visiting the holy shrines there (for religious purpose only during Thursday. On the other hand, Saef Saad quarter represents the highest percentage of trips coming to the city center as indicating in Figure 18. These trips represent the trips coming for either to the governmental offices or marketing.

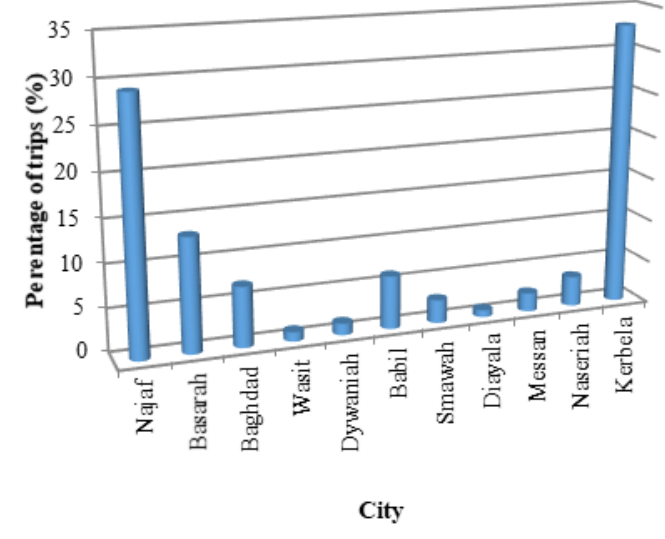

Fig. 16. Origin for trips on Thursday.

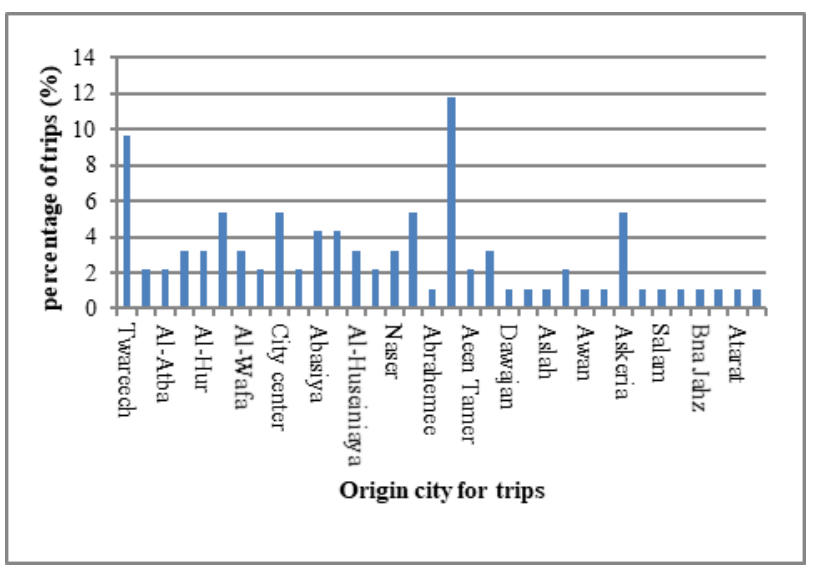

Fig. 17. Origin for internal trips on Wednesday.

\section{The results analysis}

According to the analysis of the results for five parks, it was found that most parks operated under their capacities on Wednesday except Al-Gadeer parks as 
indicated in Figures 11 to 16 . Whereas on Thursday, all parks are oversaturated except Al-Gadeer, which was closed after 2:00 P.M.

At this site, the peak period for looking at park starts after 5:30 P.M and about 6:30 all parks are overcapacity $(100 \%)$. A lot of vehicles can't get a space for parking for more than 1 hour. Other vehicles park even on arbitrary location as on-street parking in the road networks existing in the area under study. In addition, this period is the period of evening pray in the holy shrine for the visitors coming to performance their pray at Thursday evening. Moreover, the peak hour for pedestrian crossing the main road is about 5:30 P.M as shown in Figure 8.

Regarding to the peak flow rate, it was observed that the peak hour occurred on Wednesday morning. However, at this time the parks still worked under their capacities. This could be attributed that for morning flow rate, there are several destinations for these purpose such as just passing for another city because of existing AlGarage Al-Mud but for Thursday all trips have one destination is for religious issues coming to the holy shrines there. So, all spaces in the area under study were occupied by even illegal parks with high number of pedestrian crossing the main roads towards the city center. The accessibility to these parks is so limited and created congested problems on the main road.

\section{The suggested smart park}

This study has just determined the location of proposed one multi-story park from Kerbela Municipality. The location of this multi-story park has been suggested in the center of these five parks multi-stories. In fact, the suggested location is so suitable for some reasons. Firstly, its location is in the center of studied parks. Secondly, it is located in the closest site to the holy shrines (the destination for the most visitors coming through this direction). The number of spaces is briefly introduced in this study.

The total number of spaces suggested for the multistory park ranges from 700 to 850 for different layouts. For example, for option no.1 (850), the number of spaces is 100 for base, 140 for ground floor, 232 for each first and second floor, and 148 for roof. So the total number of spaces for multi-story park (850) is about double for the current total spaces for all parks (440).

Referring to the mentioned literatures about smart parks in the above sections, this study suggests using such smart park with using sensors for each parking space and connecting that with variable message in order to indicate the availability of spaces in the multi-story proposed park as indicated in Figures 1, 2 and 3. Specific sensors could be implemented for all spaces and connected with the variable messages which are placed on the main roads to indicate the availability of spaces in the park. This will help more in saving time and reducing congestion in the main road.

On the other hand, the management of routes entering the proposed multi-story park has different options. These options start from current case of entering and leaving from the main road in front of this park. The other option is from behind the park location (i.e. the parked vehicles entering or leaving the park without entering the main road as indicated in Figure 19. The VISSIM simulation model has been used to test the route of traffic in case of coming and leaving the multi-story park from the main road. This option shows that the main road suffers from congestion which is so close to what happened in reality. Another option is summarized using routes as indicated in Figure 19. This option allows no congestion on the main road because the coming and leaving demand for the park comes from determined routes in the figure which do not connect with the main road.

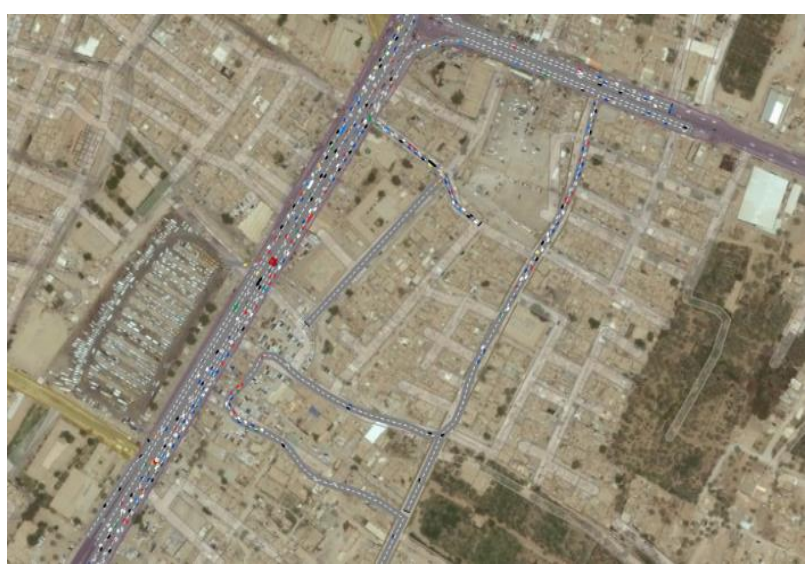

Fig. 18. Managing entering and leaving the proposed park using VISSIM model.

There is a need for effective steps which should be implemented such as:

- Followed effective parking management strategies as used in the developed countries (as mention in Section 2).

- Regulating the parking area in order to encourage the transit use and create much vibrant street life.

- Avoiding accumulative of parking spaces over a small area resulting in chaos.

\section{Conclusions and recommendations}

The main conclusions are:

1. The evaluated isolated off-street parks operate under their capacity on Wednesday but these parks suffer from overcapacity on Thursday due to religious issue. This also accompanies with high pedestrian volume crossing the roads.

2. The demand for parking every Thursday night is high around the city center. However, the high demand during special event has been excluded in this study. Therefore, there is a need for constructing multi-story parks in the area understudy and applying smart park principle for it and using variable message on the main road showing the occupancy for parks.

3. Managing pedestrian movement crossing the main road using footbridge or tunnel taking into consideration pedestrian movement resulting from parking area. 
Using SPS for the proposed multi-story park by connecting sensors in the park with variable messages on the main arterial road.

\section{References}

1. Middleeasteye.net,http://www.middleeasteye.net/ne ws/arba-karbala-pilgrims-iraq-581628397(2016).

2. G. Surpris, Evaluating the Effect of Smart Parking Technology on Campus Parking System Efficiency using Discrete Event Simulation (PhD Thesis, Embry-Riddle Aeronautical University, Florida, 2012).

3. R. Maccubbin, Evaluating ITS parking management strategies: A systems approach (Unpublished master's thesis). University of Virginia, 2000).

4. R. Lu, X. Lin, H. Zhu, and X. Shen, IEEE INFOCOM, 1413-1421, (2009).

5. J. Chinrungrueng, and U. Sunantachaikul, International Symposium on Applications and the Internet Workshops (2007).

6. B. Yan-Zhong, S. Li-Mun, Z. Hong-Song, Y. TingXin, and L. Zheng-Jun, Acta Automatica Sinica, 32(6), 968-977(2006).

7. Y. Geng, and C. Cassandras, Social and Behavioral Sciences 541278 - 1287(2012).

8. S. Adhatarao, O. Alfandi, A. Bochem, and D. Hogrefe, IEEE (VNC, 2014).

9. M. Srotyr, M. Jerabek, Z. Lokaj, and T. Zelinka, (Smart Cities Symposium Prague, IEEE, 2015).

10. A. Majidi, H. Polat, and A. Çetin, IEEE, 4th ICSG,(2016). 